\title{
Persistent Post-Traumatic Orbital Cerebrospinal Fluid Fistula with Multiple Episodes of Meningitis: Systematic Case Review and Case Report
}

\begin{abstract}
Glaucia Suzanna Jong-A-Liem¹, Carlos dos Reis Lisboa-Neto², Fernando Mendes Paschoal Junior ${ }^{3}$, Ana Carolina Maués de Oliveira', Edson Bor-Seng-Shu ${ }^{4}$, Manoel Jacobsen Teixeira ${ }^{4}$, Eric Homero Albuquerque Paschoal ${ }^{2,3}$
\end{abstract}

\section{Abstract}

Background: Orbital cerebrospinal fluid (CSF) fistulas are very rare. Most of these fistulas spontaneously heal within a couple of days and usually do not require surgical repair. Furthermore, they present low rates of complications.

Case presentation: We report a case of a 15-year-old boy that suffered a penetrating head trauma and developed multiple episodes of meningitis due to a persistent orbital and nasal CSF fistula. He underwent multiple different procedures to correct the dural breach: sphenoidal endoscopic approach, and three craniotomies, the last one succeeded with the placement of autologous grafts and biological glue. A lumbar-subarachnoidal peritoneal shunt was placed to aid for 5 days. The CSF fistula ceased to drain and he recovered of the meningitis with additional standard antibiotics.

Review: A systematic review in MedLine, Embase and Lilacs, identified 15 reported cases of persistent orbital CSF fistulas post-trauma. Traffic accidents were the most common mechanism of trauma. Most cases were reported in young boys and the main clinical manifestation was persistent "oculorrhea". The CSF leaks were traced with CT-scans and were predominantly managed surgically. No fatal outcomes were reported.

Conclusion: The reported cases raise awareness for persistent orbital CSF fistulas. Early diagnosis and adequate management is crucial to prevent complications, which are rare, but can be highly morbid and fatal.
1 Faculty of Medicine, Universidade do Estado do Pará, Belém, PA, Brazil.

2 Division of Neurosurgery, Hospital Ophir Loyola, Belém, PA, Brazil

3 Division of Neurology and Neurosurgery, Hospital Universitário João de Barros Barreto da Universidade Federal do Pará, Belém. PA, Brazil

4 Division of Neurosurgery, Hospital das Clínicas da Faculdade de Medicina da Universidade de São Paulo, São Paulo, SP, Brazil

\section{Contact information:}

Eric Homero Albuquerque Paschoal.

Address: 3100 Rua dos Mundurucus, Office 1201. Belém, PA, Brazil. Postal code: 66.040-033.

Tel: +559132663571

Đ ericpaschoal@yahoo.com.br

Keywords

CSF Fistula; CSF Leak; TBI; Complications; Meningitis; Adolescent; Oculorrhea. 


\section{Introduction}

Cerebrospinal fluid (CSF) fistulas are a well-known complication of head trauma [1]. These fistulas form communications between the subarachnoid space and an internal or external cavity. They usually are a result of fractures and dural tearing in the skull base [2], causing CSF to leak through the nasal, middle ear or orbital cavity [18]. Nasal and middle ear fistulas are a lot more common and are justified by the physical features inherent to these cavities [1, $18,7]$. Orbital CSF fistulas are very rare $[2,16]$ and manifest as orbitocele, blepharocele [7], chemosis, or excessive tearing ("oculorrhea") $[13,16]$. Most of these fistulas spontaneously heal within a couple of days and usually do not require surgical repair. Furthermore, they present low rates of complications $[6,11]$. However, rare cases of persisting fistulas are reported, which require surgical management with dural reconstruction, especially when associated to complications.

We report a case of a teenage boy, who developed posttraumatic orbital and nasal CSF fistulas. These were only diagnosed after the presentation of multiple episodes of bacterial meningitis and delayed manifestations of oculorrhea and rhinorrhea. The boy underwent multiple surgical procedures for dural repair.

\section{Case Report}

A 15-year-old male suffered a penetrating head trauma while hunting in the woods. As he fired his old shotgun, the handle expelled a thin piece of wood right through the epicanthic fold of his left eye (in a left to right direction). He did not lose consciousness. His brother removed the piece of wood and took him to an emergency unit for medical evaluation. The patient had an unremarkable medical history and he was not taking any prescription medications.

He presented no signs of respiratory distress, his blood pressure was normal; pulse was stable, and no signs of external bleeding. He was alert and oriented, times three (to person, place, and time), cooperative, and obtained a score of 15 on the Glasgow coma scale. His left eye presented conjunctival hemorrhage and a discretely swollen periorbital area. His pupils were isochoric with a reduced direct photomotor reflex on the right eye and consensual photomotor reflex in the left eye. The patient referred blindness in the right eye. His initial CT scans showed evidence of a short linear fracture in the medial wall of the left orbicular cavity and through the ethmoidal bone (Figure 1). There were no intracranial hemorrhages and no signs of dural tear or other fractures. The patient stayed hospitalized for observation for 5 days. He remained clinically stable and was discharged with no complains and a good performance status of 0 , except for his right eye blindness.

Figure 1: CT scan in axial cuts, which evidences the fracture and tracks the path of the penetrating wooden foreign body. In A, you can see the track and the edema caused by the penetrating injury. In $B$, an arrow demonstrates the path the foreign body traced through the medial wall of the left orbital cavity and nasal cavity, crossing the middle line through the ethmoidal cells penetrating in the skull base at the parasselar region of the sphenoid causing a lesion to the contralateral optic nerve.

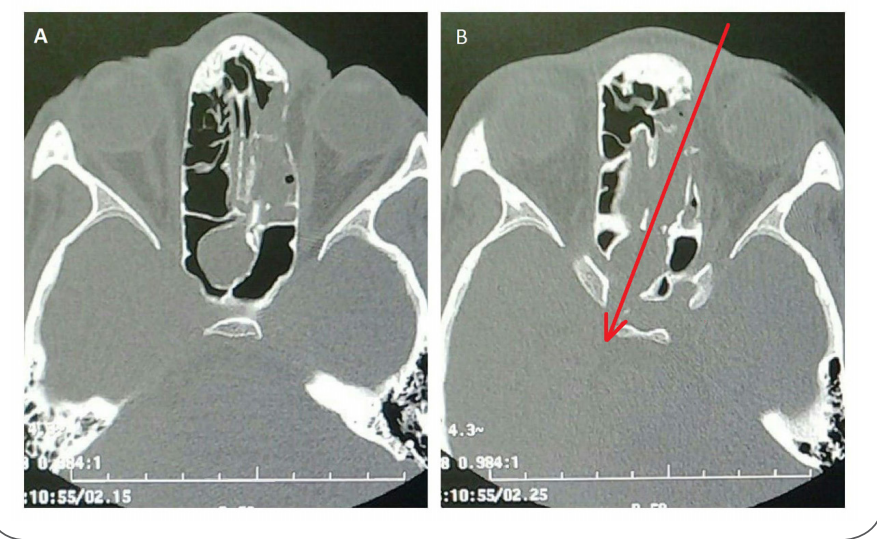


Figure 2: $\mathrm{MRI}$ in T1 weighted evidencing the left temporal meningoencephalitis.

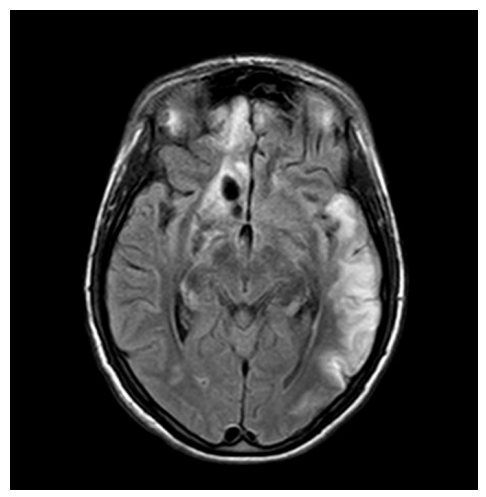

Six days post-discharge, the patient returned to the emergency unit with headache, fever, photophobia, neck stiffness, seizures, and discrete intermittent rhinorrhea. The patient was diagnosed with bacterial meningitis and was transferred to the Hospital Universitário João de Barros Barreto Medical Center for infectious diseases. He began treatment with standard antibiotic therapy for bacterial meningitis. Despite the rapid diagnosis and institution of appropriate antibiotic treatment, he did not respond very well. He developed progressive right hemiparesis and impaired level of consciousness. His MRI scans showed a hyperintense area in the left temporal lobe, suggesting meningoencephalitis (Figure 2). Over the course of two weeks, he presented recurrent meningitis, which progressively disabled him.

A neurosurgical consult was requested to evaluate the persistent rhinorrhea and the recent appearance of a clear liquid drainage through the conjunctiva of the left eye. A post-traumatic CSF leak was suspected and the drained liquid was tested for beta-2-transferin. The results came back positive, confirming the CSF leak. For surgical planning, the patient also underwent a metrizamide CT cisternography that trailed the CSF fistulas towards the nasal and orbital cavity.

At first, the neurosurgical team in cooperation of the ENT team attempted a less invasive approach to correct the dural breach. Therefore, the patient was submitted through an intranasal endoscopic trassphenoidal surgery and synthetic dural patches were placed around the fractured area. The procedure was uneventful, but did not show satisfactory results.

Given the persistence and associated infectious complications, the patient underwent surgical management for dural repair with placement of synthetic dural patches in attempt to cease the CSF leaks. The procedure was uneventful, but did not stop the CSF leaks. Postoperatively the patient worsened clinically and evolved with Broca's aphasia and meningoencephalitis together with an incisional empyema. Hence, he was taken back to the OR for surgical drainage. His neurological deficits kept worsening; therefore, a more radical approach was necessary to repair the dural tear.

The case was discussed in neurosurgical rounds and the board decided to do another transcranial approach as soon as he reached the minimal clinical conditions. The board suggested to retrieve autologous grafts of muscle, fascia lata and adipose tissue of the patient's left leg. These grafts added by surgical glue (N-Butyl-Cyanoacrilate) were used to line the anterior base of the skull bilaterally. The procedure was uneventful and post-operatively the patient ceased to drain CSF through the nasal and orbital cavity. A lumbar-subarachnoidal peritoneal shunt was placed to aid for 5 days. He continued on antibiotics and did not develop any new episode of meningitis after surgery. He was discharged with performance status 3, right eye blindness and right hemiparesis.

\section{Discussion}

Penetrating head injuries can cause serious damages even through a small wound entry $[14,17]$. CSF fistulas occur when a penetrating head injury causes a skull fracture and breaches the underlying layers of meninges [4]. Despite this being a common complication, described in 15 to $20 \%$ of head injuries 
Table 1. Systematic review based on the MOOSE guidelines in MedLine, Embase and Lilacs using various combinations of the terms "orbital CSF fistula","cranioorbital fistula", "posttraumatic", "tbi". 36 studies were included for further analysis and 15 met the inclusion criteria for this review [3, 16, 13, 12, $20,10,22,18,2,8,23,17,7,5,1]$.

\begin{tabular}{|c|c|c|c|c|c|c|c|}
\hline$\#$ & Author, Year & $\begin{array}{l}\text { Gender/ } \\
\text { Age* }^{*}\end{array}$ & Mechanism & Clinical manifestation & Complication & Diagnosis & Treatment \\
\hline 1 & Bagolini, 1957 & $\mathrm{~N} / \mathrm{I} / 9 \mathrm{~m}$ & Car accident & $\begin{array}{c}\text { Oculorrhea }+ \text { Hematoma of upper eyelid }+ \\
\text { Anisocoric }\end{array}$ & $N / I$ & $N / I$ & Surgical \\
\hline 2 & Joshi, 1978 & $\mathrm{~F} / 8 \mathrm{~m}$ & Car accident & Rhinorrhea + Oculorrhea & - & Dextrostix test + CT scan & Transcranial surgery + Dural repair \\
\hline 3 & $\begin{array}{l}\text { Garza-Mercado, } \\
1982\end{array}$ & $\mathrm{M} / 20$ & Assault & $\begin{array}{l}\text { Oculorrhea + Edema of Eyelids + } \\
\text { Ecchymosis + Limited EOM }\end{array}$ & $N / I$ & $N / l$ & Surgical \\
\hline 4 & Sibony, 1985 & $M / 27$ & Car accident & Orbitocele + Proptosis & $\begin{array}{l}\text { Cerebral abscess } \\
\quad+\text { Phlebitis }\end{array}$ & Cisternography & Conservative \\
\hline 5 & Dryden, 1986 & $M / 4$ & Car accident & Oculorrhea for 2 years & Meningitis & Dextrostix test + CT scan & Transcranial surgery + Silastic implant \\
\hline 6 & Till, 1987 & $\mathrm{M} / 14 \mathrm{~m}$ & $\begin{array}{l}\text { Stabbing } \\
\text { wound }\end{array}$ & Oculorrhea & $N / I$ & Dextrostix test + CT scan & Surgical \\
\hline 7 & Salame, 2000 & $\mathrm{~F} / 20$ & Sport injury & Oculorrhea & $N / I$ & Physical exam + Glucose test & Conservative \\
\hline 8 & Arslantas, 2003 & $\mathrm{~N} / \mathrm{l} / 3$ & Fall & Orbitocele & $N / I$ & CT scan + MRI & Transcranial surgery + Dural repair \\
\hline 9 & Civelek, 2006 & $M / 7$ & $\begin{array}{l}\text { Occupational } \\
\text { accident }\end{array}$ & $\begin{array}{c}\text { Proptosis + Diplopia + Periorbital abscess + } \\
\text { Orbital cellulitis + Oculorrhea }\end{array}$ & $N / I$ & $\mathrm{~N} / \mathrm{l}$ & Surgical \\
\hline 10 & Twaij, 2009 & $M / 3$ & $\begin{array}{l}\text { Penetrating } \\
\text { orbital injury }\end{array}$ & Orbitocele + Proptosis + Periorbital edema & $\begin{array}{l}\text { Reduced visual } \\
\text { acuity }\end{array}$ & MRI & Conservative \\
\hline 11 & Pereira, 2011 & $\mathrm{~F} / 7 \mathrm{~m}$ & Gunshot injury & $\begin{array}{l}\text { Luxation of globe }+ \text { Oculorrhea }+ \\
\text { Ecchymosis }+ \text { Eyelid hematoma }\end{array}$ & Blindness & CT scan + surgical exploration & $\begin{array}{c}\text { Transcranial surgery + Sponge block + } \\
\text { Organic glue }\end{array}$ \\
\hline 12 & Chandra, 2013 & $F / 4$ & $\begin{array}{l}\text { Blunt head } \\
\text { injury }\end{array}$ & Upper eyelid swelling & $N / l$ & CT scan & Transcranial surgery + Dural repair \\
\hline 13 & Pease, 2013 & $\mathrm{M} / 22$ & Car accident & Oculorrhea + Limited EOM & - & CT scan & $\begin{array}{l}\text { Transcranial surgery + Skull base } \\
\text { reconstruction }\end{array}$ \\
\hline 14 & Borumandi, 2013 & $\mathrm{~F} / 49$ & Fall & Eyelid swelling + Ecchymosis & $N / /$ & CT scan + MRI & Conservative \\
\hline 15 & Apkarian, 2014 & $\mathrm{M} / 34$ & Car accident & Periorbital swelling + Periorbital pain & $N / l$ & $\begin{array}{c}\text { CT scan + Beta-2-transferrin } \\
\text { test }\end{array}$ & Conservative \\
\hline
\end{tabular}


[15], orbital CSF fistulas are rare [21, 18]. A systematic review found 15 reported cases (Table 1). The rareness of this presentation is justified by protective anatomical characteristics, including: (a) the usually intact conjunctiva, unfavorable for the formation of a CSF exit. (b) the sinus walls, which are thinner than the orbital walls and, therefore, easier to fracture based on the principle of least resistance $[16,4]$. (c) the orbital cavity, which is considered a virtual space with a zeroed internal pressure [18], main reason the orbital CSF leaks are asymptomatic or course to a spontaneous resolution [21].

Based on the speed of the penetrating head injury, these can be classified in high and low speed injuries [14]. This case describes an injury caused by a high speed and low temperature foreign object (wood), which caused the fracture in the left orbital cavity, crossed the ethmoidal sinus in the midline and immediately damaged the right optic nerve. Low temperature injuries are more prone to local infections, as reported in this case, different from high speed and high temperature injuries, such as gunshot wounds. Penetrating injuries by wooden foreign objects carry a higher risk of infection [17].

Penetrating wounds require thorough investigation and for this, the follow recommendations are important: never underestimate the internal damage; do not pull out the foreign object without medical support, such careless removal can induce bleeding and lead to fatal consequences [14]. The brother of our patient inadvertently removed the foreign object and could have worsened the damages of the injury. Moreover, the third recommendation is that no part of the object should remain in the injured tissue. The remnant of foreign objects in penetrating head injuries can lead to post-traumatic complications like meningitis and brain abscess. This case described a penetrating head trauma with a wooden foreign object which is a rare cause of orbital lesion [17]. Wooden foreign objects are hard to be seen by CT-scans and therefore difficult to evaluate [14].
Any patient with a head injury and excessive drainage through the orbital conjunctiva or excessive "tearing" should be suspected to have CSF oculorrhea, especially when concomitant with rhinorrhea [13]. Nonetheless, these clinical presentations can go unrecognized [16], as most of the fistulas resolve spontaneously in 24 to 48 hours. The fistula closes by the adhesion of blood products and inflammatory cells at the site of the breach, herniation of the brain tissue into the traumatic defect [16], or by the proliferation of fibrous tissue or mucosa over the laceration [15].

When a post-traumatic fistula is suspected, CTscans can be useful to detect the bone fractures that caused the CSF leak. To confirm the presence of the CSF leak, the output liquid can be tested for glucose levels above $30 \mathrm{mg} / \mathrm{ml}$ or for the presence of beta-2-transferrin. Some authors suggest to routinely test the lacrimal and nasal secretions of patients with anterior fossa fractures in high-energy traumas, especially in infants or young adults [13]. For surgical planning, some surgeons can request a CT-cisternography (metrizamide) to track the fistula [20].

After identifying the leak, the goals of therapy for fractures of the skull base include the prevention of intracranial infections, decompression of intracranial nerves, and if necessary, repair of vessel compression [15]. If the leak is not clinically evident and no other major injuries are present, prophylactic surgery is not recommended [19]. The administration of prophylactic antibiotic therapy remains controversial but helps to decrease the morbidity and mortality caused by skull base fractures [15]. Conservative treatment is the standard approach when the leak ceases spontaneously within a week, or when the fracture is small or not visible. This conservative approach includes measures to prevent intracranial hypertension and CSF drainage. If the orbital CSF leak does not fulfil the above-mentioned requirements for conservative treatment, a surgical repair can be conducted via a transcranial or an endona- 
sal approach [15]. For the surgical plan, the dural breach and fistula need to be identified. The dural breach can be corrected with sponges, dural grafts, fibrin or organic glue, reinforced by sutures $[17,15]$. In case the dural tear is not identifiable, a layer of muscle plug and grafts of fascia can be placed over an extended suspected area to seal the fistula [9]. In our case, we lined the anterior base of the skull with surgical glue, dural graft, and autologous tissue from the fascia lata, muscle and adipose layer, which showed to be effective in closing the dural breach, leading to its cure.

\section{Conclusion}

It is important to early diagnose and treat persistent orbital CSF fistulas. These fistulas are diagnosed by a suggestive clinical presentation (excessive tearing), CT-scans, lacrimal secretion testing and by CT-cisternography with metrizamide. Associated complications are rare, but when present can be highly morbid. This case report demonstrates a different surgical strategy to approach persistent CSF fistulas. Therefore, we emphasize that the awareness and fundamental understanding of the lesion is essential to diagnose the condition for successful management.

\section{Patient consent}

The patient's legal guardian signed a consent form approving the submission of this case to the journal. The Ethics Board of the Ophir Loyola Hospital approved our report.

\section{Acknowledgements}

The authors would like to thank the research group "Grupo de Ensino e Pesquisa em Doenças Cerebrovasculares/UFPA" for the support in compiling this paper.

\section{Conflicts of interest}

The authors declare that they have no conflict of interest.

\section{References}

1. Apkarian AO, Hervey-Jumper SL, Trobe JD (2014) Cerebrospinal fluid leak presenting as oculorrhea after blunt orbitocranial trauma. J Neuroophthalmol 34:271-273

2. Arslantas A, Vural M, Atasoy MA, Ozsandik A, Topbas S, Tel E (2003) Posttraumatic cerebrospinal fluid accumulation within the eyelid: a case report and review of the literature. Childs Nerv Syst 19:54-56

3. Bagolini B (1957) Leakage of spinal fluid into upper eyelid following trauma. Arch Ophtalmol 57:454-456

4. Bhatoe HS (2002) Blepharocele after head injury. Skull base 12:73-76

5. Borumandi F (2013) Traumatic orbital CSF leak. BMJ Case Rep DOI:10.1136/bcr-2013-202216

6. Brodie HA (1997) Prophylactic antibiotics for posttraumatic cerebrospinal fluid fistulae. A meta-analysis. Arch Otolaryngol Head Neck Surg 123:749-752

7. Chandra N, Ojha BK, Chandwani V, Srivastava C, Singh SK, Chandra A (2013) A rare case of posttraumatic eyelid swelling: cerebrospinal fluid blepharocele. J Neurosurg Ped 11:242-244

8. Civelek E, Bilgic S, Kabatas S, Hepgul KT (2006) Penetrating transorbital intracranial foreign body. Ulus Travma Acil Cerrahi Derg 12:245-248

9. David CA, Catalano PJ (2002) Commentary to article "Blepharocele after head injury" by Bhatoe, H. S. Skull base $12: 76$

10. Dryden RM, Wulc AE (1986) Pseudoepiphora from cerebrospinal fluid leak: case report. Br J Ophthalmol 70:570-574

11. Friedman JA, Ebersold MJ, Quast LM (2000) Persistent posttraumatic cerebrospinal fluid leakage. Neurosurg Focus 9:e1

12. Garza-Mercado R, Aragon-Lomas J, Martinez-Garza J, LealHernandez L (1982) Cerebrospinal fluid blepharocele: an unusual complication of head injuries. Neurosurgery 11:525-526

13. Joshi KK, Crockard HA (1978) Traumatic cerebrospinal fluid fistula simulating tears. Case report. J Neurosurg 49:121-123. doi:10.3171/jns.1978.49.1.0121 
14. Kawamura S, Hadeishi H, Sasaguchi N, Suzuki A, Yasui N (1997) Penetrating head injury caused by chopstick-case report. Neurol Med Chir 37:332-335

15. Mandrioli S, Tieghi R, Galie M, Denes SA, Pagliaro F, Clauser L (2008) Anterior skull base fractures: guidelines for treatment. J Craniofac Surg 19:713-717

16. Pease M, Marquez Y, Tuchman A, Markarian A, Zada G (2013) Diagnosis and surgical management of traumatic cerebrospinal fluid oculorrhea: case report and systematic review of the literature. J Neurol Surg Rep 74:57-66

17. Pereira FJ, Bettega ABP, Cruz AVV (2011) Fístula liquórica traumática com luxação de globo ocular: relato de caso. Arq Brasileiros Oftalmol 74:58-60

18. Salame K, Segev Y, Fliss DM, Ouaknine GE (2000) Diagnosis and management of posttraumatic oculorrhea. Neurosurg Focus 9:e3

19. Schreckinger $M$, Orringer $D$, Thompson BG, La Marca F, Sagher O (2011) Transorbital penetrating injury: case series, review of the literature, and proposed management algorithm. J Neurosurg 114:53-61

20. Sibony PA, Anand AK, Keuskamp PA, Zippen AG (1985) Posttraumatic cerebrospinal fluid cyst of the orbit. Case report. J Neurosurg 62:922-924. doi:10.3171/jns.1985.62.6.0922

21. Terao H, Sato S (1975) Ventriculo-orbital fistula in closed head injury. Case report. J Neurosurg 43:754-756. doi:10.3171/ jns.1975.43.6.0754

22. Till JS, Marion JR (1987) Cerebrospinal fluid masqueradin as tears. South Med J 80:639-640

23. Twaij S, Viswanathan $P$, Page $A B$ (2009) Acute traumatic orbital cerebrospinal fluid cystocele mimicking orbital abscess. J AAPOS 13:491-493

Publish in International Archives of Medicine

International Archives of Medicine is an open access journal publishing articles encompassing all aspects of medical science and clinical practice. IAM is considered a megajournal with independent sections on all areas of medicine. IAM is a really international journal with authors and board members from all around the world. The journal is widely indexed and classified Q1 in category Medicine. 